\title{
Vida y trabajos de un ilustrado desconocido: don Tomás Fermín de Lezaún.
}

\author{
Ernesto Viamonte Lucientes \\ I.E.S. Isabel Perillán y Quirós \\ Campo de Criptana, Ciudad Real
}

Resumen

Don Tomás Fermín de Lezaún (1747-1778) es un ilustrado zaragozano socio fundador de la Real Sociedad Económica Aragonesa de Amigos del País y miembro de la Real Academia de la Historia. Autor, — pese a su corta vida_, de un ingente número de trabajos, - hasta 36 entradas consigna Latassa en su Biblioteca Nueva-, buena parte de los cuales, lamentablemente, no están localizados. El presente artículo pretende dar a conocer las obras que poseemos de Lezaún que, tanto por su cantidad —algo más de 20—, como por su calidad, —su nombre es comúnmente alabado en los más variados estudios—, y por su variedad - poesía, historia, numismática, geografía, etc-, nos demuestran a las claras que Lezaún merece ser algo más que una mera referencia.

\section{Introducción}

Un ejemplo entre tantos. Don Ricardo del Arco, en su Repertorio de manuscritos referentes a la historia de Aragón de 1942, señala a don Tomás Fermín de Lezaún como uno de los aragoneses que más se destacaron en el xvIII junto a personalidades de la talla de Piquer, Luzán, Nasarre, Martínez Salafranca, Nifo, Jordán de Asso, Félix y José Nicolás de Azara, etc. He empezado el trabajo con la 
afirmación un ejemplo entre tantos, porque son muchas las ocasiones en que podemos encontrarnos el nombre de Lezaún citado, — meramente citado-, por lo general elogiosamente ${ }^{1}$.

Pero volvamos a Del Arco y reparemos en que cualquiera de los nombres aludidos por él son sobradamente conocidos. Sin embargo, ¿qué sabemos de la vida de Lezaún?, ¿en qué empresas estuvo embarcado?, ¿estamos ante un elogio hiperbólico o ponderado? A estas preguntas espera contestar el presente trabajo.

\section{La vida de don Tomás Fermín de Lezaún}

Como he señalado, son numerosísimos los manuales o repertorios en los que se cita a Lezaún. La mayor parte de alusiones se limitan a nombrarlo; otras, las menos, nos aportan algún dato más sobre su vida y su obra. No obstante, en lo que se me alcanza, la práctica totalidad de trabajos en los que ocurre lo último indicado, no hacen sino repetir la información que nos aporta la magna publicación de don Félix de Latassa y Ortín, Biblioteca Nueva de los escritores aragoneses que florecieron desde el año de 1753 hasta el de 1795. Se puede afirmar que, salvo las escuetas aportaciones de Cacho y Salas Ausens, no hay estudioso que no beba en Latassa ${ }^{2}$. Debo, por lo tanto, acudir a tal fuente para perfilar la vida de nuestro ilustrado.

Lezaún nació en la ciudad de Zaragoza un 18 de septiembre de 1747 en el seno de una familia noble. Sus padres fueron doña Teresa de Tornos y don Pedro de Lezaún, ciudadano de la misma urbe y Oficial Primero de la Contaduría Principal del Ejército y Reino de Aragón, y también Archivero por Su Majestad del Reino.

${ }^{1}$ Véase, R. DeL Arco, Repertorio de manuscritos referentes a la historia de Aragón, Madrid, C.S.I.C., 1942. Otra muestra: J.F. Forniés Casals, La Real Sociedad Económica Aragonesa de Amigos del País en el período de la Ilustración (1776-1808): sus relaciones con el artesanado y la industria, Madrid, Confederación Española de Cajas de Ahorro, 1978, pág.40, defiende a Lezaún cuando habla de la importante obra de Francisco Aguilar Piñal, Paula de Demerson y Georges Demerson, Las Sociedades Económicas de Amigos del País en el siglo XVII. Guía del investigador, San Sebastián, s.n., 1974. Forniés denuncia la falta de atención, comparada con su importancia, de los investigadores hacia la Económica Aragonesa. Incluso llega a señalar ciertos errores concretos, entre ellos la incompleta enumeración de la nómina de cargos directivos de la Institución. Entre éstos habla de la notable ausencia de Lezaún como Segundo Secretario.

${ }^{2}$ F. de Latassa y Ortín, Biblioteca Nueva de los escritores aragoneses que florecieron desde el año de 1753 hasta el de 1795, Pamplona, Joaquín Domingo, 1801. M.T. Сасно, [Un dance aragonés de 1723], en Estudios en Homenaje al Dr. Don Antonio Beltrán, Zaragoza, Facultad de Filosofía y Letras, 1986, pags. 1193-1201. J.A. Salas Ausens, [Introducción] al Estado eclesiástico y secular de las poblaciones y antiguos y actuales vecindarios del Reino de Aragón de don Tomás Fermín de Lezaún, Zaragoza, Cortes de Aragón, 1990. 
Sobre don Tomás Fermín dice Latassa lo siguiente:

La erudita y amena literatura en que se distinguieron sus estudios y talentos, ilustró mucho en él aquella laboriosidad, desvelo y amor a su patria y su nación que hicieron el carácter de su espíritu y adelantaron tanto las esperanzas que mereció en los progresos de aquellas letras, cuando ya éstos no eran pequeño ornamento de juventud, en que murió ${ }^{3}$.

Sirvió Lezaún en la Contaduría del Ejército, en la cual llegó a ser Oficial. Estuvo casado con doña Librada de Sorribas, hija de don Juan, Regidor de Zaragoza, y de doña Catalina Lázaro. Como se verá, hizo Lezaún gala de sus luces y conocimientos en la Real Sociedad Económica de Amigos del País establecida en 1776 en la ciudad de Zaragoza.

También nos informa Latassa de cómo el zaragozano mejoró el Mapa del Reino de Aragón, debido originariamente a don Juan Bautista Labaña, y cómo la Real Academia de la Historia, dado el celo con el que desarrolló tal labor, hizo a Lezaún individuo suyo con expresiones muy honoríficas para su persona.

Lezaún muere el 15 de noviembre de 1778, entre las tres y las cuatro de la mañana, a resultas del incendio del Teatro de la ciudad de Zaragoza acaecido el día 12 del mismo mes, mientras se representaba una ópera conmemorando los días del Príncipe de Asturias, el futuro Carlos IV ${ }^{4}$.

Poco más se puede leer acerca de la vida de nuestro autor en la Biblioteca Nueva. Mucho más relevantes son las informaciones que contiene acerca de su obra, de la que me ocupo más adelante. Pero también mediante estos datos podemos entrever algo de la personalidad del ilustrado aragonés. Así, nos informa

${ }^{3}$ Latassa, Ob. cit., pág. 272. En todas las referencias a texto o citas modernizo ortografía y puntuación, a excepción de los nombres propios.

${ }^{4}$ El Coliseo zaragozano, inaugurado en 1771, era reputado como uno de los mejores de España. El incendio sucedió la tarde del 12 de noviembre de 1778 y no estuvo totalmente controlado hasta entrada la noche. Los fallecidos en la tragedia, o a consecuencia de ella, fueron gentes de toda condición social. El mismo día del suceso murieron un total de 60 personas; 17 más lo hicieron en días posteriores, entre ellos Lezaún; otras 52 personas se contaron como maltratadas y heridas por el mismo motivo. La información más detallada del suceso nos la proporciona un testigo: T. Sebastí́n y Latre, Relación histórica de los sucesos ocurridos en Zaragoza con motivo del incendio de su Coliseo en la noche del doce de noviembre de 1778..., Zaragoza, Francisco Moreno, 1779. Véanse también al respecto: A. Egido, Bosquejo para una historia del teatro en Aragón hasta finales del siglo xVII, Zaragoza, Institución Fernando el Católico, 1987 y E. Viamonte Lucientes, [E] Coliseo de Comedias de Zaragoza en llamas, Heraldo de Aragón, 15 de noviembre de 1993, pág. 18.

Consecuencia del incendio fue la suspensión de las representaciones teatrales durante un tiempo. Hasta e 25 de agosto de 1799 no habrá un nuevo teatro en Zaragoza, aunque entre el 78 y el 99 se siguió representando en teatros improvisados. Véase al respecto, E. Viamonte Lucientes, un ejemplo de oratoria antiilustrada: el sermón del Padre Bruno al incendio del Coliseo de Zaragoza, Actas de las V Jornadas de Castilla-La Mancha sobre investigación en archivos: iglesia y religiosidad en España, en prensa. 
don Félix de Latassa del cuidado que ponía Lezaún en recoger papeles originales de diversos asuntos, - en muchos casos ejerciendo él mismo de copista-, merced a lo cual contamos con una importante reunión de noticias y documentos. Además de esta colección de papeles varios, Latassa apunta también la existencia de una biblioteca de nuestro autor. Libros y papeles que fueron a parar, en primera instancia, a dos destinatarios: el Doctor don Manuel Turmo, Canónigo penitenciario de Zaragoza, y a don Tomás Sebastián y Latre, quedando algunos otros en la casa nativa de nuestro autor.

También nos puede orientar acerca de la personalidad de Lezaún don Isidoro Antillón, quien unos veinticinco años tras la muerte del ilustrado, hace un elogio abierto tanto de su figura como de su labor. Define a Lezaún, por ejemplo, como [un sujeto de cuya ilustración se esperaba el más cumplido desempeño]. Y destaca su particular aplicación a las bellas letras, progresos en la anticuaria e historia, celo infatigable por los intereses y gloria de su patria, vasta y sólida erudición en distintos ramos de literatura ${ }^{5}$.

Desafortunadamente, mis intentos por ahondar en la biografía de Lezaún no han dado los frutos deseados ${ }^{6}$. Los únicos datos útiles al respecto proceden de la obra manuscrita del zaragozano. De tales papeles podemos deducir que Lezaún estudió en la Compañía de Jesús de Zaragoza, donde descolló por su interés por las lenguas clásicas y la creación literaria. De esa época se conserva en la Biblioteca Universitaria de Zaragoza, en el volumen manuscrito que figura con la signatura 240, la obra titulada Tragedia del Cónsul Bruto, que se representó en latín en el Colegio de la Compañía en Zaragoza, dentro de una distribución de premios de Retórica y Poesía, celebrado en 17 de junio de 1763, es decir, cuando Lezaún contaba con 16 años.

También sabemos, gracias a los mencionados escritos personales del ilustrado, que a mediados de los sesenta residió en Madrid, seguramente por razón de su carrera militar, y que siguió las dos vocaciones paternas, la de las armas y la de archivero: la primera sin mucho interés ni dedicación temporal, a pesar de que era importante también dentro de la familia materna, y la segunda apasionadamente.

Igualmente conocemos por referencias, y por los restos que aún quedan en la Biblioteca de la Universidad de Zaragoza, su notable biblioteca y que poseía

\footnotetext{
${ }^{5}$ I. DE Antillón, Noticias históricas sobre el Mapa de Aragón que levantó en el siglo $17^{\circ}$ el cosmógrafo Juan Bautista de Lavaña, Variedades de Ciencias, Literatura y Artes, IV y II (1804), págs. 16-32 y 81-94.

${ }^{6}$ Por ejemplo, los intentos por obtener información de los Archivos del Ejército han sido infructuosos, pese a la buena disposición de sus custodios en todo momento. Tanto el Archivo General Militar de Segovia como el Servicio Histórico Militar de Madrid carecen de expediente personal, hoja de servicios o antecedente alguno relacionado con Lezaún.
} 
un interesante museo, fruto de su curiosidad por las medallas, monedas y antigüedades. La colección estaba presidida, — como era de esperar-, por los retratos de don Antonio Agustín y de don Vicencio Juan de Lastanosa ${ }^{7}$. Y el dato no parece mera curiosidad, sino una demostración de su preocupación por la historiografía crítica española.

Esto es lo que puedo aportar, hasta la fecha, acerca de la vida de Lezaún. Afortunadamente, son mucho más relevantes las informaciones sobre su obra.

\section{La obra de don Tomás Fermín de Lezaún}

Si no he podido recabar muchos datos respecto a la vida de nuestro ilustrado, bastante más he podido profundizar en lo que respecta a su obra. Nuevamente debo comenzar por la abundante información de Latassa. La mera nómina que contiene el apartado dedicado a Lezaún nos da cuenta de sus múltiples intereses e inquietudes y hace que podamos calificarlo plenamente de ilustrado. Las entradas de obras pertenecientes a la pluma de don Tomás Fermín que nos da Latassa alcanzan la cifra de 36. No las transcribo por dos motivos: la necesidad de un espacio del que carezco para este trabajo y, especialmente, la ilocalización, esperemos que temporal, de una buena cantidad de las mismas, por lo que prefiero centrarme en las que sí poseemos hasta la fecha ${ }^{8}$. No obstante, como se verá a continuación, los trabajos que nos quedan son de suficiente calado como para sacar del olvido a la figura de don Tomás Fermín de Lezaún.

Procedo a establecer dos grandes apartados: un primero dedicado a los trabajos del ilustrado que han visto la luz en las imprentas, ya sea en ediciones contemporáneas al autor, ya sea en ediciones posteriores; un segundo referido a los manuscritos de Lezaún que tenemos.

\subsection{Impresos}

2.1.1 Clarín sonoro de la Fama...

La primera obra, cronológicamente hablando, que dio Lezaún a las imprentas es este Clarín sonoro / de la Fama / que convoca las Musas / a celebrar en acordes suaves metros / al máximo entre sus héroes, / y aun mayor que su fama, / el Excelentísimo Señor / don Pedro Pablo Abarca de Bolea / Ximénez de Urrea, / Conde de Aranda, / Marqués de Torres. / Narración puntual / de los poetas y poetisas célebres que ha / tenido su nobilísima ascendencia. / Hecha / por el más

\footnotetext{
${ }^{7}$ Véase, M.T. Сасно, Ob. cit., págs. 1193-1194.

${ }^{8}$ Véase F. de Latassa, Ob. cit., págs. 273-281.
} 
fiel aragonés y afecto criado / del dicho Excelentísimo Señor, a quien dedica su debida veneración / este poema heroico, cuyo manuscrito, con pocas correcciones, se conserva en la Biblioteca Universitaria de Zaragoza con la signatura Ms. 389, bajo el título conjunto de Poesías varias de diferentes poetas que ha recogido en este libro don Tomás Fermín de Lezaún. La obra, en su impresión, carece de fecha, pero gracias a la versión manuscrita, que lo declara, sabemos que se estampó en Zaragoza el 31 de agosto de 1769 y que se imprimieron un total de 550 ejemplares, siéndole entregado un par de ellos al Conde de Aranda. Constan de 24 páginas numeradas, que contienen el cuerpo del texto, en verso, y notas en prosa a pie de página. A buen seguro es obra escrita en Zaragoza y apresuradamente, como se puede leer en un añadido al título que aparece en la versión manuscrita, que afirma que fue realizada en 24 horas. El ejemplar que contemplo pertenece a la Biblioteca Universitaria zaragozana con la signatura Caja: 19-420 Ar. Es composición a la que se alude en diferentes escritos, por ejemplo, en la Biblioteca Nueva de Latassa. Fue impresa en Zaragoza en la imprenta del Rey Nuestro Señor.

La composición consta de 448 versos endecasílabos, formando un romance heroico en el que riman los pares en $-\mathrm{a}-0$, y que comienza: Ninfas gloriosas del soberbio Pindo... Tiene varias partes claramente marcadas, aunque aparezcan en el texto sin pausa que las separe: invocación a las Musas; breve elogio del Conde de Aranda; ponderación del ilustre linaje del loado, prestando atención a las empresas literarias; extenso elogio de Aranda en comparación con los héroes clásicos, enalteciéndolo tanto en las letras como en las armas, y detallando algunas de sus empresas; encomendación a cada Musa del canto de una de las vertientes en las que sobresale el loado. Las notas que aparecen a pie de página a lo largo del texto explican la estirpe de don Pedro Pablo, o bien aclaran a quiénes se refieren algunos de los nombres propios que aparecen en el poema, por ejemplo los de las Musas. Son de la mano de Lezaún, como se deduce por el contenido de la nota $\mathrm{m}^{9}$.

\subsubsection{Enmiendas al Mapa de Aragón de J.B. Labaña}

Juan Bautista Labaña (1555-1624) era cosmógrafo y cronista de Felipe III cuando, en la segunda década del siglo XVII, le fue encargado por los diputados aragoneses un mapa de Aragón con todos los pueblos y accidentes del territorio. Labaña que, sin duda alguna, era la persona adecuada se trasladó al terreno. Fruto de su viaje, mientras recorría Aragón, además del mapa, fue la escritura

${ }^{9}$ En ella, entre las informaciones usuales, se puede leer... Me he esmerado en escribir los varones ilustres florecientes en las letras que ha tenido esta Casa... El uso de la primera persona lo dice todo. 
de un cuaderno de notas pronto conocido como Itinerario del Reino de Aragón ${ }^{10}$.

En 1615 Labaña dio un borrador en pergamino que, con algunas rectificaciones, fue el posteriormente grabado, hacia 1617-18, por el conocido artista Diego de Ástor. Sería un primera versión que constituyó el primer mapa dibujado del territorio de Aragón. La segunda versión es la enmendada de 1777 con el añadido de importantes datos, nueva información sobre las ciudades y sus funciones y la incorporación de la red de caminos. Tales enmiendas fueron hechas por don Tomás Fermín de Lezaún.

El mapa inicial tuvo una gran demanda durante los siglos XVII y XVIII, siendo la última de todas las impresiones la mencionada de 1777. La versión oficial, acerca de esta postrera edición del mapa, es casi legendaria. Dice que, a pocos días de estar concluida, ante el temor de que el documento cayera en manos de los franceses, y con el pretexto de no estar bien señaladas las fronteras con Francia, una gran parte de los ejemplares de la edición efectuada por Lezaún fue secuestrada por la autoridad competente. Seguramente tal medida afectó igualmente a las planchas, las cuales están hoy en día desaparecidas. Incluso el padre de Lezaún, don Pedro, intentó remediar tal situación tras la muerte de su hijo. Por más que tras muchas instancias se declaró que el mapa podía publicarse de nuevo sin escrúpulo, de hecho la prohibición, por diversas causas, nunca fue levantada totalmente, Pese a ello, posteriormente el mapa servirá de base a múltiples cartógrafos por su diseño y precisión.

Tanto el original de Labaña como los retoques de Lezaún han sido trabajos muy elogiados. Así lo hace, por ejemplo, el geógrafo aragonés don Isidoro de Antillón a inicios del $\mathrm{xIX}^{11}$.

Aunque parece ser que por llevar a cabo tal labor don Tomás Fermín no recibió otra recompensa que el aplauso de los inteligentes, la calidad de la misma fue valedora en el nombramiento del zaragozano como académico de la Historia. El mencionado Antillón nos ayuda a conocer un poco más el talante de nuestro ilustrado, al narrarnos su actuación cuando la impresión del mapa hecha por él fue secuestrada:

\footnotetext{
${ }^{10}$ Para un conocimiento preciso de la vida y de la obra de don Juan Bautista Labaña, e incluso de la ciencia de la cartografía a lo largo de la historia, es sumamente útil el trabajo de A. Hernando Ricla, La imagen de un país. Juan B. Lavaña y su mapa de Aragón (1610-1620), Zaragoza, Diputación Provincial, Institución Fernando el Católico, 1996. También es muy interesante para ver cómo se gestó el mapa el artículo de P.F. de Lezaún, Mapa de Aragón, Boletín de la Real Academia de la Historia, LXXIX (1921), págs. 320-361.

${ }^{11}$ Véase al respecto, I. DE ANTILLón, Ob. cit., que se ocupa de las adiciones y enmiendas hechas por Lezaún en las entradas 23, 24, 25, 26 y 27. Véase también, A. Hernando Ricla, Ob. cit., págs. 141-149. Allí, bajo el epígrafe Anexo II, incluso se reproduce el artículo de don Isidoro de Antillón. Véase asimismo, P.F. DE Lezaún, Ob. cit., págs. 350-361.
} 
Las contestaciones que de aquí se originaron con Lezaún prueban, de un modo superior, que éste poseía aquella franqueza y docilidad, aquella modestia y decoro que son tan propios de los sabios y de los verdaderos patriotas como ajenos de los ignorantes y mercenarios escritores. Llenáronse con estas ocurrencias de amargura y dolor los últimos días del joven aragonés... ${ }^{12}$.

El Mapa de Aragón de Labaña que mejoró Lezaún fue editado por la Diputación Provincial de Zaragoza, acompañando al Tomo VII de la Sección Histórico-doctrinal de la Biblioteca de Escritores Aragoneses, donde aparecía la obra de Lezaún de la que nos ocuparemos a continuación: la Declaración sumaria. El texto se copió del original depositado en la Universidad de Leyden por encargo de Jordán de Asso ${ }^{13}$.

Con posterioridad, un facsímil del primer estado ha sido realizado por el Instituto Geográfico Nacional de Madrid en 1989. El original del que se extrajo se halla en manos privadas. Ejemplares de sus diversas ediciones figuran en buen número de cartotecas como la de la Biblioteca Nacional o la del Museo Naval, y fuera de España se puede encontrar en bibliotecas importantes como la Nacional de París o la British Library de Londres.

El mapa mejorado por Lezaún, por consiguiente, es de fácil consulta. La Institución Fernando el Católico de la Diputación Provincial de Zaragoza tiene aún en sus fondos editoriales ejemplares del primero. Y el Archivo y Biblioteca de Palacio de Madrid conserva un ejemplar del mapa de Lezaún, sin montar, además del texto que le acompaña ${ }^{14}$. También se puede consultar en la Biblioteca Universitaria de Zaragoza con la signatura An. 7-2 a -1.

Como queda dicho, la edición llevada a cabo por Lezaún en 1777 incorpora numerosas adiciones que rejuvenecieron y completaron la imagen del mapa original de Labaña. Además de las inserciones arriba mencionadas, y de colocar numerosos datos que figuran en la leyenda de signos convencionales, dibujó una cartela que reza así:

El Intendente general del Estado y Reino de Aragón y Corregidor de su capital, don Juan Felipe de Castaños, mandó retocar este mapa y aumentar los caminos, año de 1761. De orden de don Manuel Antonio de Larrea y Ripa, Intendente

\footnotetext{
${ }^{12}$ A. Hernand Ricla, Ob. cit., pág. 147.

${ }^{13}$ Véase, J.B. Labaña, Itinerario del Reino de Aragón, Zaragoza, Imprenta del Hospicio Provincial, 1895, Tomo VII y también el Prólogo que J.M. Casas Torres pone a I. DE Asso, Historia de la economía política de Aragón, Zaragoza, Guara Editorial, 1983, págs. VII-XX, en especial la pág. XXVIII.

14 Véase, A.P. Uвіето Artur, El ‘Itinerario de Aragón’ (1610-1611) de Juan Bautista Labaña, en Estudios del Departamento de Historia Moderna, Zaragoza, 1985, págs. 155-172.
} 
interino y Contador principal, a aumentar, corregir e ilustrar. Y se publicó completo y perfeccionado, siendo Intendente general de las mismas, Estado y Reino, don Bartolomé de Pont, por don Thomás Fermín de Lezaún y Tornos, año de 1777.

El mapa, en suma, se enriqueció con numerosas adiciones, muchas de ellas fruto de los cambios experimentados por el territorio. Pues hay que tener en cuenta que en los más de 150 años transcurridos desde la primera estampación, Aragón había sufrido multitud de cambio demográficos, económicos y de mejora en las comunicaciones. En esencia las variaciones fueron las siguientes: inclusión en el mapa de los límites de los corregimientos; aumento de 326 poblaciones; corrección de 122 nombres; bautismo de 33 ríos; rectificación de algunos defectos y errores de menos calado. Coronó su labor con una explicación histórica del origen del mapa, su autoridad y documentos con que se formó ${ }^{15}$.

\subsubsection{Declaración sumaria de Lezaún}

La importancia del Mapa de Aragón de Juan Bautista de Labaña ha quedado clara. Pero por si fuera poco, tenemos las manifestaciones de dos importantes plumas aragonesas que se ocuparon de la labor del cosmógrafo.

Lupercio Leonardo de Argensola escribió una Declaración sumaria de la historia de Aragón para la inteligencia del Mapa; Tomás Fermín de Lezaún hizo lo propio con un Prosigue la 'Declaración sumaria de la historia de Aragón’ y principalmente de este Mapa para su más perfecta inteligencia ${ }^{16}$.

Esta segunda obra aparece fechada en Zaragoza a 11 de diciembre de 1777 por su autor. En ella Lezaún da cuenta de la gestación del mapa de Labaña. También hace una breve historia de otros mapas que con posterioridad al que le ocupa ha habido. Explica, igualmente, su labor en la mejora del Mapa de Aragón. Comenta cómo recabó información para la realización de las enmiendas a Labaña.

\footnotetext{
${ }^{15}$ En la página 55, de la obra mencionada de A. Hernando Ricla, se puede ver una sección del mapa rectificado por Lezaún que puede compararse con la misma sección del original en página 54. Mediante el cotejo se aprecia la riqueza de datos aportada por Lezaún, así como la útil incorporación de signos utilizados para expresar las categorías empíricas de la realidad. Los datos que detallamos proceden de I. de AnTILLón, Ob. Cit., p.147.

${ }^{16}$ Ambas obras se pueden encontrar en J.B. Labaña, Ob. cit., págs. 201-207 y 209-214, respectivamente. En el prólogo de la edición, don Faustino Sancho y Gil relata cómo al señor don Ángel María de Pozas es quien le ha hecho llegar la Declaración sumaria de la historia de Aragón de Lupercio Leonardo de Argensola continuada por Lezaún para su estampación en la Biblioteca de Escritores Aragoneses. Don Faustino, en el Prólogo a la obra, pormenoriza también la labor realizada por Lezaún en el Mapa de Aragón, pero no hace sino repetir las palabras de don Isidoro de Antillón, con la retórica propia del momento en que escribe. Prácticamente, la única variación que introduce es el elogio que hace de Lezaún al narrar la retirada del Mapa por las autoridades, pág. XXXVII.
} 
Y termina detallando, muy pormenorizadamente, todas su aportaciones. Interesa, especialmente, el juicio de Lezaún acerca del mapa sobre el que trabajó, es decir, el de Labaña. Dice al respecto nuestro ilustrado que son poquísimas las poblaciones que no están señaladas con toda la debida exactitud, siendo la causa, para las que ahora se han aumentado, estar colocadas con error las próximas, o por descuido de Labaña, a que aun los hombres más inteligentes están expuestos, o culpa de ajustarse el grabador al diseño que tuvo presente ${ }^{17}$.

\subsubsection{Estado eclesiástico y secular de las poblaciones y antiguos y actuales vecindarios del Reino de Aragón}

En abril de 1778 la Real Academia de la Historia, por medio de un aviso de don José Miguel de Flores, nombraba a Lezaún académico, a la vez que solicitaba su colaboración en un proyectado Diccionario Geográfico de España. En tal encomienda parece haber tenido mucho que ver la actividad desarrollada por don Tomás Fermín en el seno de la Real Sociedad Económica Aragonesa, y en particular algunos trabajos de carácter histórico que allí realizó, a los cuales me referiré más adelante, así como la reedición del mapa elaborado por Labaña a inicios del xvi. Fruto de la petición de colaboración mencionada es el Estado eclesiástico y secular.

La obra se conserva en un manuscrito de 1778 en la Biblioteca de la Real Academia de la Historia con la signatura Ms. 9-26-1-4762. Además es de lo poco de Lezaún que está editado, en este caso por José Antonio Salas Ausens ${ }^{18}$.

El Estado eclesiástico y secular es, como queda dicho, sólo la primera parte de un encargo para el Diccionario Geográfico de España de la Academia de la Historia. Al Estado, que vendría a ser una primer entrega, le seguirían otras con variada información acerca de accidentes geográficos: cadenas montañosas, corrientes fluviales, noticias sobre localidades, etc. Se trata de un estudio eminentemente informativo, que ofrece noticia puntual de cuantas referencias ha podido encontrar sobre el conjunto de la población aragonesa, valiéndose, también, de fuentes anteriores. El bloque central del estudio lo constituye la relación individualizada de todos lo núcleos de población aragoneses distribuidos por corregimientos y número de familias. La información se completa con otros datos relativos a la comunidad: casas habitadas y derruidas, número de parroquias, pertenencia a realengo o señorío, diócesis de la que depende, distancias de cada núcleo a la sede del corregimiento. También incluye el trabajo una relación con la ubicación de los monasterios y conventos aragoneses, cerrándose

\footnotetext{
${ }^{17}$ J.B. Labaña, Ob.cit., pág. XXVIII.

${ }^{18}$ Véase nota 2.
} 
con el vecindario de la Zaragoza de 1723 y el estado de la hacienda de los zaragozanos en $1725^{19}$.

La experiencia del Mapa debió ser fundamental para la elaboración de este trabajo, ya que la Academia de la Historia solicitó los servicios de Lezaún el 9 de abril de 1778. El 7 de julio del mismo año ya tenía el zaragozano la primera parte del cuestionario requerido.

Los resultados del Estado eclesiástico y secular son desiguales, aunque meritorios. Como observa Salas Ausens, las prisas con que la obra fue elaborada le restaron precisión. Así, se puede observar que la información sobre las poblaciones no es completa ni homogénea; tampoco lo es la información sobre los corregimientos. Sin embargo, Salas le atribuye un gran acierto: la homogenización del marco territorial, lo que facilita una rápida comparación entre localidades y circunscripciones. Pese a ello, el trabajo de Lezaún ha de usarse con precaución, en especial en lo que respecta a la fiabilidad de las cifras ofrecidas ${ }^{20}$.

Sumamente interesantes son las palabras que don Tomás Fermín pone, a modo de introducción, al Estado eclesiástico y secular. Están fechadas el 7 de julio de 1778 y firmadas por él. Las dedica A la Real Academia de la Historia. Allí nos informa del porqué de la obra y de su gestación. Nombra las fuentes que ha consultado para la elaboración de la misma. Así, por ejemplo, afirma que el trabajo es deudor de los documentos utilizados en la mejora del Mapa de Labaña. También hace unas observaciones acerca de su propia labor como historiador y geógrafo. Y nos informa de que tiene abundantes datos para publicar, en un futuro, una contrastada historia de Zaragoza. De todas las afirmaciones que hace en este preámbulo se desprende un talante abiertamente ilustrado, como ocurre cuando critica un tipo de hacer historiográfico fabuloso, alejado de lo que él mismo pretende hacer con estudios como el presente y también de las líneas de trabajo que se iban imponiendo en la Academia de la Historia, o como se deriva de las siguientes letras:

La averiguación de las antigüedades de los pueblos, su etimología y demás que pide la instrucción impresa es materia muy difusa y llena de dificultades para poner en claro la verdad como se desea, pues el demasiado amor a la patria de algunos escritores, y los fines particulares de otros, como a Vuestra Ilustrísima es notorio, y puede servir d ejemplo mi patria Zaragoza ${ }^{21}$.

\footnotetext{
${ }^{19}$ Véase al respecto, J.A. SALAs Ausens, Introducción, Ob. cit., págs. 11 y 17-18. Los corregimientos de los que se ocupa la obra de Lezaún son los siguientes: Zaragoza, Albarracín, Alcañiz, Barbastro, Benavente, Borja, Calatayud, Cinco Villas, Daroca, Huesca, Jaca, Tarazona y Teruel.

${ }^{20}$ Véase, Ibid., págs. 17-19.

${ }^{21}$ Véase Ibid., págs. 4-5.
} 
Tras esta obra, parece evidente que Lezaún pensaba tomarse su actividad de académico con la dedicación que en él era seña de identidad. Así se desprende de la celeridad con la que acudió al requerimiento de la Academia, teniendo en cuenta, en todo momento, que este Estado eclesiástico y secular no era sino en avance de una obra de muchísima mayor envergadura. Prestemos atención a las siguientes palabras del citado preámbulo:

Yo procuraré adelantar, cuanto me sea posible, la formación del Diccionario Geográfico que me tiene encargado y remitir a Vuestra Ilustrísima con la distinción correspondiente las cédulas de las poblaciones de este Reino con arreglo a la instrucción comunicada. Entre tanto admita Vuestra Ilustrísima en esta obra, de que Vuestra Ilustrísima se dignará hacer el uso que le pareciere conveniente, los deseos que me asisten de emplearme en cuanto sea de su obsequio. Zaragoza 7 de julio de 1778.

\subsubsection{Comercio libre de Indias...}

El trabajo cuyo título completo es Noticia / de los Reales Decretos / y Cédulas / sobre el comercio libre de Indias. / Y / real facultad para el reconocimiento I del río Ebro con el objeto de facilitar su navegación y po / ner corriente el camino carreteril a Tortosa, concedida a instancia de la Real Sociedad Económica de Amigos / del País, establecida en la imperial ciudad / de Zaragoza, fue el último que Lezaún realizó para la Económica Aragonesa, institución que decidió de inmediato su impresión.

Está fechado en marzo de 1778 y consta de 54 páginas. En la primera aparece, en el recto, el título, la Empresa de la R.S.E.A.A.P., debida a Lezaún, y el lugar y la fecha de impresión: Zaragoza, en la imprenta de don Luis de Cueto, año de 1778.

El ejemplar que manejo pertenece a la Biblioteca Universitaria de Zaragoza con la signatura Caja: 25-270-Ar. Pero es obra que puede consultarse en diversas librerías como la de la Económica Aragonesa. A ella se alude en diferentes escritos: en el libro de Registros de dicha Sociedad y también lo hacen Latassa y don José Pasqual de Quinto ${ }^{22}$.

El Comercio libre de Indias... se abre de la siguiente e ilustrada manera:

La felicidad de un reino consiste en que el monarca que lo gobierna, dedicado al bien de sus vasallos, procure con el mayor desvelo facilitar por todos los medios la riqueza y la abundancia.

${ }^{22}$ J. Pasqual de Quinto, Catálogo de las publicaciones e impresos de la R.S.E.A.A.P., 1776-1982, Zaragoza, Real Sociedad y Caja de Zaragoza, Aragón y Rioja, 1983. 
Es por eso por lo que Carlos III, —es decir, Campomanes-, auspició la formación de las Sociedades Económicas. La primera parte del opúsculo está dedicada a glosar tal tipo de instituciones y las labores que realizan, con especial atención a la Sociedad Aragonesa. A partir de ahí entra en materia. Inicialmente se ocupa de las dos posibles vías carreteriles de enlace con el Mediterráneo: por Tortosa y por Vinaroz. Pasa a continuación al punto que más le interesa: el de la navegación del Ebro. Sobre tal particular comienza haciendo una breve historia de los intentos por navegar por dicho cauce fluvial. Luego informa de la creación de una Junta el 6 de junio del 77, en el seno de la Económica Aragonesa, para fomentar tal proyecto, y de los diversos pasos dados para llevar a cabo tal empresa ${ }^{23}$. A continuación entra en el cuerpo propiamente dicho de la obra. Primeramente informa de la preocupación que existía entre las gentes inquietas del Reino de Aragón acerca de que el comercio con las Indias sólo pudiera canalizarse por el puerto de Cádiz y cómo era intención de las mismas solicitar del Monarca cierta flexibilidad de tal salida. Afortunadamente, antes de que la petición se curse, Carlos III liberaliza el comercio con las Indias por medio de un Real Decreto de fecha 2 de febrero de 1778. Decreto que fue enviado por Floridablanca a la Sociedad junto a una carta del mismo el 24 de febrero de dicho año. Ambos documentos los reproduce Lezaún en el impreso.

Una vez superada la mayor de las trabas, la Sociedad se propone estimular el comercio con las Indias. Se reproducen también dos Reales Resoluciones en las que se señalan diversos pagos y aranceles que han de realizar los comerciantes. Una Resolución posterior comunica una nueva noticia que será la que estimule el presente escrito y la acción toda de la Sociedad: se trata de la comunicación de la apertura del puerto de los Alfaques de Tortosa y de el de Almería para el comercio con las Indias. El primero intenta facilitar el comercio allende los mares del Reino de Aragón y con el segundo se intenta hacer otro tanto con la zona de Murcia y Granada.

El escrito de Lezaún termina dándonos cuenta de que en la Junta de la Real Sociedad Económica celebrada el 20 de marzo del 78 se aprueba la publicidad de lo anterior, con el fin de intentar fomentar el anhelado comercio con las Indias. Tal, y no otro, es el objeto del presente escrito elaborado por Lezaún.,

El opúsculo se cierra, como queda dicho, con la reproducción de la Real Cédula... que ordena habilitar los dos puertos mencionados para los intercambios más allá de los mares. El Real Decreto lleva fecha 16 de marzo, mientras que la Cédula es del 29 del mismo mes y año. Se imprime, finalmente, una

${ }^{23}$ Informa Lezaún acerca de una carta enviada por el Conde de Floridablanca sobre tal particular, con fecha 20 de enero de 1778. El dato puede ilustrar bien a las claras la política de corte centralista del gobierno de Carlos III. 
carta con fecha 11 de abril del 78 de don Pedro Escolano al Conde de Sástago que presenta la decisión anterior.

\subsection{Manuscritos}

2.2.1 Tratado de las monedas jaquesas de Sobrarbe y Aragón

El Tratado de las monedas jaquesas de Sobrarbe y Aragón. Su origen, curso, alteraciones y providencias para su perpetuidad, tanto de las de cobre ligado con plata, como de las de plata y oro, con el valor que han tenido en distintos tiempos. Defensa del blasón antiguo del Reino y Reyes de Sobrarbe. Cronología de ellos y de los de Aragón por sus monedas. Demonstración y explicación de las que han batido dichos Reyes, con lo demás que comprende, es el título íntegro de un volumen iluminado con diseños de más de cien medallas, monedas, escudos y otros signos públicos con el imaginario blasón de Sobrarbe.

En el interesantísimo Prólogo al lector, que aparece como papel suelto, aparte de valerse de los tópicos al uso, - hablar del interés de la materia que trata, aludir, en una finta de captatio benevolentiae, a sus escasos méritos—, Lezaún data la pieza. Advierte que compuso el trabajo por indicación de fray Manuel Abad y Lasierra, monje de San Juan de la Peña, cuando en 1772 estuvo en Zaragoza el año anterior. Fue el religioso quien viendo que yo tenía alguna inteligencia en materia de monedas antiguas, y bastantes noticias de nuestro Reino, me pidió quisiese tomar a mi cuidado la defensa del antiguo Reino de Sobrarbe, que es el principal de su obra por las monedas. Lezaún confiesa haber dado su palabra sin reparar en las grandes dificultades de la empresa, estando tentado en múltiples ocasiones posteriores a abandonarla, por los muchos obstáculos que hallaba. Admite que es la primero obra de alguna entidad que ha compuesto, y acaba diciendo:

No dudo que hallarás muchos motivos para la crítica, que como es la primera obra de alguna entidad que he compuesto, su asunto difícil y ninguna mi experiencia, estará sujeta a muchos yerros. Pero sin que llegues a darlos al público, yo te estimaré me los adviertas, seguro de que admitiré con gusto cualquiera corrección y asunto mínimo en cualquiera otra obra que publique, de alguna de entre otras que tengo empezadas. Te doy palabra de publicarla.

La obra la destinó Lezaún al archivo del Monasterio de San Juan de la Peña, siendo entregada al mismo por su hermano. Este original se halla hoy en el Archivo de la Corona de Aragón, en Barcelona, con la signatura Ms. 144 (antigua '136'). Se trata de un manuscrito sin fechar que consta de 25 hojas más otra que hace las veces de portada. De la 1 a la 6 se puede leer el Discurso preliminar, que 
contiene, según indica el propio autor, Origen de las monedas, sus inventores, materiales y otras cosas de que se han formado en distintos tiempos; su perfección, su curso en España desde los siglos más antiguos; dineros y óbolos de Aragón; motivos de escribirse esta obra y división de ella. De la 7 a la 25 recto aparece la obra propiamente dicha: Monedas jaquesas de Sobrarbe. Se divide en Introducción y 15 apartados más.

Estamos ante un manuscrito autógrafo, escrito en prosa y en lengua española. Antes de pertenecer al Archivo de la Corona de Aragón, estuvo en manos del Abad Andrés Casaus y Torres, hasta la Desamortización. Parece proceder del Monasterio de San Cugat del Vallés.

El estudio de Lezaún, —de un joven Lezaún, recordemos que es, según confesión propia, su primera labor de cierta entidad—, nos lo muestra en su faceta de historiador, — no sólo de un erudito—, pues va más allá de la mera recopilación de datos. Por ejemplo, refuta ardorosamente la opinión del P. Moret, el cual negaba ser hereditaria, en los Reyes y Reino de Aragón, la divisa de Sobrarbe, y mantenía que no se descubrían estas armas en signos o sellos de cartas reales, en fábricas antiguas de Reyes, ni en sus sepulcros, lápidas o monedas. Que el mismo Lezaún es consciente de su labor, se desprende de sus palabras en la hoja 7:

Bien sé yo que me expongo a la crítica de aquellos que quieran seguir al Arzobispo Marca en su Historia de Bearne, a Moret en sus Investigaciones históricas (...) y a otros muchos que niegan la antigüedad y monedas del primitivo Reino de Sobrarbe...

Pero para valorar la calidad de historiador de don Tomás Fermín de Lezaún en su justa medida, lo mejor es acudir a voces más autorizadas. Don Ricardo del Arco observa que nuestro autor, aunque defiende las caprichosas afirmaciones legendarias hechas sobre Sobrarbe en el siglo xvII, totalmente desacreditadas por la historiografía seria, tiene como mérito indudable y justificación el de alegar fundamentos dignos de atención para justificar el valor de la moneda jaquesa y su emblema, además de dar un buen número de noticias $\operatorname{curiosas}^{24}$.

${ }^{24}$ Véase al respecto, R. DEL Arco, Un tratado inédito sobre la moneda jaquesa, Linajes de Aragón 24 (1913) Tomo IV, págs. 461-472, especialmente la pág. 468. Una vez más sale enjuiciado en su manera de trabajar Lezaún. Una valoración, la de Del Arco, que añadir a las ya vistas a lo largo del trabajo: la de Isidoro de Antillón acerca de las enmiendas hechas al Mapa de Aragón de Labaña, o la de Salas Ausens acerca del Estado eclesiástico y secular. Pero lo que creemos que habla de la fiabilidad como estudioso de nuestro ilustrado es el hecho, señalado anteriormente, de que la Academia de la Historia le encomendase la elaboración del apartado concerniente al Reino de Aragón del Diccionario Geográfico de España, en un tiempo en el que en la tierra de Lezaún no faltaban excelentes especialistas. 


\subsubsection{Estado antiguo de la cría de caballos en el Reino de Aragón}

Este trabajo es un manuscrito que el zaragozano compuso para la R.S.E.A.A.P., con el ilustrado propósito de fomentar una actividad que estaba cayendo en alarmante abandono. El escrito se titula Estado antiguo de la cría de caballos en el Reino de Aragón. En la hoja 11 aparece la firma y la rúbrica de su autor: Thomás Fermín de Lezaún, tras las cuales se lee el siguiente texto: Entregado al Excelentísimo Señor Conde de Sástago en () de enero de 1777. Hay que decir que dicha fecha aparece desleída en las dos últimas cifras del año y totalmente ilegible por lo que respecta al día. Por lo tanto el año de 1777 no deja de ser mera conjetura. Ángel Canellas en su Inventario del Archivo de la R.S.E.A.A.P. cita esta obra con la entrada 488. Pero incluye el escrito dentro del año 1790 , lo que constituye un evidente error ${ }^{25}$. La obra, sin lugar a dudas, la escribió Lezaún en el tiempo en el que perteneció a la Económica, es decir, en los años de 1776, 77 ó 78. Examinado el escrito me inclino por 1777. En todo caso, la letra de este añadido del que hablamos coincide con la de la firma, es por lo tanto de nuestro ilustrado, pero no ocurre lo mismo con la letra del cuerpo del texto.

El documento consta de 16 hojas sin numerar y está escrito por completo en prosa y en lengua española. No consta su lugar se escritura, pero es muy probable que fuese en Zaragoza. El manuscrito fue propiedad del Conde de Sástago, como se deduce del añadido que va tras la firma de Lezaún. Actualmente el único ejemplar que conozco pertenece a la Real Sociedad Económica Aragonesa de Amigos del País y se conserva en su sede zaragozana con la signatura Caja - 42-488. El texto no ha sido publicado ni reproducido en parte alguna.

El escrito comienza analizando la importancia de la cría de caballos en el Reino de Aragón antaño. Para ello pondera los servicios que hicieron los aragoneses a distintos monarcas contribuyendo a su servicio, en distintas ocasiones, con el envío de hombres a caballo. Un repaso a los diversos Registros de Cortes le permite llegar a la conclusión de que la cría de caballos en Aragón fue sumamente floreciente hasta el principio del siglo en el que se escribe el opúsculo. A continuación pasa a dar ejemplos que testimonian la riqueza caballar de la región: cita a Estrabón que la elogia; la coronación de Alonso IV con un increíble despliegue de equinos; el privilegio que concedió el Rey don Pedro a los ciudadanos de Zaragoza en 1348 que previene, entre otras cosas, de que se tengan por ciudadanos honrados los que tengan para su uso caballería propia; y la Previsión en las Cortes de Teruel del año de 1428 del Rey don Alonso,

${ }^{25}$ A. Canellas, Inventario del archivo de la R.S.E.A.A.P., Zaragoza, Librería General, 1988. 
sumamente beneficiosa para la cría de caballos, que se mantuvo durante 20 años y que fue conocida como Equis multiplicandis.

Una vez debidamente argumentada la riqueza equina, analiza las causas de su disminución, que Lezaún achaca, fundamentalmente, a la pérdida de poder y de autoridad por parte de los ricos-hombres y a la extinción de las caballerías de honor. Como es patente, Lezaún se duele de la implacable modernidad política que provoca disminución del poder de la nobleza en beneficio de la autoridad real y del ascenso de los burgueses: ya no hay justas ni torneos que ayuden a mantener crías de caballos.

A partir de la Guerra de Sucesión, a comienzos del xviII, la desaparición progresiva del caballo va en aumento. Muchos de los grandes señores abandonaron sus estados y fueron a la Corte, despreocupándose de la cría que antes fomentaron. Con la desaparición de las justas se dejaron de armar caballeros a la usanza antigua y, por añadidura, los ciudadanos de Zaragoza perdieron sus antiguos privilegios. Todo ello, sin lugar a dudas, entraña la disminución del censo equino.

En el escrito sobresale lo mucho que lamenta la decadencia que se produce en la capital, ciudad que, recuerda, en 1642 sirvió al Rey Felipe IV con 400 caballos, cifra que equivale a la que aportaba el resto del Reino de Aragón. En la actualidad, de acuerdo con las cifras consignadas, sólo podría aportar unos 40 animales, cosa que asimismo sucede en el resto de la región.

El texto, como no podía ser menos, termina pidiendo que se frene la decadencia de la cría de caballos, y para ello aboga porque la Económica la fomente y la tome bajo se protección.

\subsubsection{Apuntaciones históricas...}

La labor de historiador de Lezaún, como poco a poco se va desprendiendo de este trabajo, tiene diversas vertientes. Ejemplo de una de ellas sería el libro titulado Apuntaciones históricas sacadas de los Registros de los actos comunes de los diputados del Reino de Aragón, desde 1469 hasta 1707 en que se extinguió su Consistorio. No cabe duda de que esta recopilación debió hacerla el aragonés en su calidad de Archivero de la Diputación del Reino. Nos lo confirma Latassa cuando nos apunta que las noticias las fue sacando de los Registros del Archivo General del Reino de Aragón. Así, los volúmenes contienen las noticias más particulares que se hallan en dichos Registros desde el año de 1469, en que empiezan dichas anotaciones, hasta el de 1707, en que se extinguió dicho consistorio. La obra, como señala Ricardo del Arco, se debe al desvelo de don Tomás Fermín de Lezaún ${ }^{26}$. Desafortunadamente la totalidad de la misma cons-

${ }^{26}$ Véase R. del Arco, Ob.cit., 1942. 
taba de cinco volúmenes de los cuales tan sólo podemos consultar los siguientes:

II (1558-1600), 195 hojas;

III (1600-1621), 102 hojas;

y V (1665-1707), 106 hojas.

Faltan, por lo tanto, el I y el IV. También poseemos el índice de cosas notables y el registro de actos comunes de 1673. Todos ellos son tomos en $4^{\circ}$, de pergamino, escritos en español y con letra del siglo XVIII, seguramente de Lezaún, que pueden hallarse en la Biblioteca Nacional con la signatura 190-192.

\subsubsection{Sumario y resumario...}

Otro gran ejemplo de la labor de historiador de Lezaún nos lo da uno de los volúmenes pertenecientes a su biblioteca. Concretamente el que se conserva en la Biblioteca Universitaria de Zaragoza con la signatura Ms. 97 y que lleva el siguiente título: Sumario y resumario de las Cortes celebradas en Aragón por sus Serenísimos Reyes. Hechos de orden de los Diputados del Reino de Aragón por Gerónimo de Blancas. Cronista del mismo Reino. Año de 1585. Se trata de un manuscrito que el mismo don Tomás Fermín data en 1585 y que tiene tal número de adiciones de mano de nuestro autor que hacen que podamos hablar de la obra como comentada por Lezaún, aunque el volumen propiamente dicho ha de atribuirse a Blancas. (Un ejemplo: las anotaciones de las hojas 34, 35 y 36 tienen mucho más texto que el propio cuerpo.) El contenido de la obra responde cabalmente al anunciado en el título, y los comentario de Lezaún son precisiones a las afirmaciones del Cronista Blancas.

El volumen se compone de 683 hojas, siendo el texto de la obra copia en letra del siglo xvi y las adiciones originales en letra del siglo xvIII. Todo ello está escrito en lengua española y en prosa. No consta el lugar de la escritura.

He de repetir una vez más que el calado de las anotaciones de Lezaún es tal que, aunque se haya de considerar como autor del Sumario y resumario a don Jerónimo de Blancas, bien puede darse la obra como comentada por Lezaún, siendo ejemplo, como queda dicho, de las múltiples caras que se faceta de historiador poesía.

\subsubsection{Los volúmenes manuscritos de Lezaún conservados en la Biblioteca}

\section{Universitaria de Zaragoza}

En la Biblioteca perteneciente a la Universidad de Zaragoza es donde se encuentra la mayor parte de las obras localizadas de don Tomás Fermín de Lezaún. Un total de 30 volúmenes que hay que dividir en dos bloques claramente diferenciados. Un primer bloque estaría compuesto por los tomos facti- 
cios de obras varias recogidas por Lezaún o de las que él mismo es autor: cartas, papeles varios, poesías, etc. Todos ellos tienen, por añadidura, otro factor en común: de la mayor parte de escritos diferentes que contienen resulta prácticamente imposible determinar los que pertenecen originalmente a Lezaún y los que no son sino un ejemplo de su curiosidad recopiladora. El segundo bloque lo compondrían los volúmenes de otros escritores y que no tienen nada que ver con nuestro ilustrado, salvo que son obras pertenecientes a su biblioteca particular. La gran diferencia entre ambos apartados es que en este último, Lezaún no tiene participación alguna, ni como creador ni como copista, aunque algunos estudiosos, como el mismo Latassa, consignan algunos de los trabajos como propios del zaragozano. En el mejor de los casos, en aquél en el que Lezaún haya tenido alguna participación activa, ésta no pasa de ser la escritura de alguna leve anotación del siempre inquieto Secretario de la Económica. Quede claro, por lo tanto, que estamos hablando de una veintena de libros, básicamente referentes a Aragón y a su historia, que, por razones de espacio, soslayo en este trabajo, y que sirven, una vez más, para percatarnos del talante ilustrado de nuestro autor.

Caso bien diferente es el del primer bloque de libros referido. Allí la cantidad y variedad de composiciones es absolutamente caótica y ciertamente indescifrable en su autoría. Hay, eso sí, una mínima parte de piezas atribuibles a Lezaún, pero como queda dicho, es muy pequeña parte. En todo caso, indicamos a continuación los títulos y algunas particularidades de los tomos pertenecientes a este bloque, ya que al menos algo de su contenido puede darse como de nuestro autor ${ }^{27}$.

Ms. 154: Noticia muy individual de todas las funciones y gloriosos hechos en que se ha hallado el Regimiento de Reales Guardias Españolas desde su creación, que fue en el año de 1704. Es un manuscrito escrito en Zaragoza en abril de 1770 . Se trata de una relación cronológica de 1704 a 1741, con apartados anuales de desigual extensión, en los cuales se da noticia de los acontecimientos más destacados acaecidos en el Regimiento de Guardias Reales desde su fundación hasta la fecha indicada. Todo el escrito se debe a Lezaún.

Ms. 155: Historia de los Generales de la Grecia, cuya vida escribió Cornelio Nepote en idioma latino y tradujo en castellano don Thomás Fermín de Lezaún y Tornos. Año 1759. Es un manuscrito que, pese a la fecha anterior, se va datando paulatinamente en la parte inferior del recto o del vuelto. Su elaboración, en verdad, va del 6 de noviembre de 1763 al 8 de febrero de 1764. Se trata de un escrito

${ }^{27}$ La signatura que precede a los títulos corresponde a la que actualmente tiene cada volumen en la Biblioteca Universitaria de Zaragoza. 
en castellano debido a Lezaún, en lo que parece un ejercicio escolar de traducción.

Además de un Prólogo del autor, una vida de Cornelio Nepote y un índice, el grueso del volumen se ocupa, si nos atenemos al directorio, de la vida y hazanas de una serie de Generales que van desde Themístocles a Tito Pomponio Ático. En realidad tal plan no se lleva a cabo, ya que la relación se acaba con Hamílcar. Faltan los siguientes Generales que estaban programados pero cuya vida no plasmó Lezaún: Haníbal, Catón, Tito Pomponio Ático.

Ms. 240: Poesías varias. Entretenimientos del discurso y ocios ocupados en que se emplea don Thomás Fermín de Lezaún. Es un manuscrito sin datar. En las diversas hojas numeradas, de la 1 a la 102, aparecen las composiciones, todas ellas poéticas, difícilmente atribuibles a un autor concreto o al propio Lezaún.

Ms. 330: Papeles varios en prosa y verso, políticos, satíricos y otros tumultos de Madrid y Zaragoza en1766, guerras de Portugal en 1762 y otros, recogidos en este libro por don Thomás Fermín de Lezaún. Manuscrito sin datar que contiene piezas muy variadas, tanto en prosa como en verso, unas parecen ser originales y otras copias. Los temas son mucho más diversos de lo que del título se pueda desprender. No suele constar el lugar de escritura, salvo en algunas cartas que lo explicitan. Ocurre otro tanto que en el volumen anterior en lo que respecta a la autoría de las composiciones.

Ms. 340: Papeles varios en prosa y versos, políticos y satíricos que recogió en este libro don Thomás Fermín de Lezaún. Manuscrito sin datación expresa, compuesto por papeles varios, los más originales, si bien parece haber alguna copia. La temática es múltiple. Algunos documentos localizan y datan su lugar de escritura. Su autoría es desconocida en la práctica totalidad.

Ms. 341: Cartas y papeles varios sobre el estado de diferentes guerras en el siglo pasado y en el presente, recogidas en este libro por don Thomás Fermín de Lezaún. Manuscrito compuesto por diferentes documentos, algunos de los cuales llevan fecha que nos permite datarlos a finales del siglo XVII. Los papeles son originales y copias. Mayoritariamente se trata de cartas. Uno de los documentos está escrito en francés. Suele poderse localizar el lugar de escritura. Ninguno de ellos, evidentemente, es de Lezaún quien actúa, simplemente como recopilador.

Ms. 387: Poesías varias. Manuscrito compuesto por obras recogidas por Lezaún, algunas de las cuales podrían ser propias. Una mínima parte viene con el nombre del autor. Las piezas no van datadas, habiendo tanto originales como copias.

Ms. 388: Poesías varias que recogió en este libro don Thomás Fermín de Lezaún. Manuscritos varios sin datación expresa entre los que hay tanto origi- 
nales como copias. Resulta prácticamente imposible precisar qué composiciones poéticas son de Lezaún, que sin duda las hay, y cuáles no.

Ms. 389: Poesías varias de diferentes poetas que ha recogido en este libro don Thomás Fermín de Lezaún. Manuscritos varios, algunos del propio Lezaún, otros de diversos autores. No hay datación expresa, si bien se puede deducir en algunas piezas. El tomo contiene obras originales y copias, e incluye una obra de teatro titulada El caballero y la dama, debida a don Antonio Baro. Algunas de las composiciones constan como compuestas en Zaragoza y son, sin lugar a la duda, de Lezaún. Tal ocurre con dos obras dedicadas al Conde de Aranda: Clarín sonoro de la Fama... y Debido sentimiento...

Los manuscritos 240, 330, 340, 387, 388 y 389 contienen un ingente número de composiciones poéticas, — más de 300_- dentro de los más variados metros, estilos y temas. El estudio y análisis de este abundante corpus poético es trabajo en el que estoy embarcado en la actualidad.

\subsubsection{Los trabajos de Lezaún para la Real Sociedad Económica Aragonesa de Amigos del País}

Anteriormente hemos tenido la oportunidad de revisar algunos trabajos de gran calado que Lezaún realizó para los Amigos del País zaragozanos: la actualización del Mapa de Labaña, el tratado sobre la cría de caballos y el informe sobre el comercio con las Indias. Pero nuestro autor desarrolló en el seno de la Económica otras muchas labores, ya que fue uno de los socios más implicados en el proyecto ilustrado ${ }^{28}$.

Allí Lezaún ocupó diversos puestos, en especial el de Secretario Segundo que, las más de las veces, ejercía como Primero. Así, en los libros de Resoluciones se pueden encontrar diversos escritos del ilustrado, ya que en ellos quedan copiadas cartas, oficios y papeles varios propios de las labores burocráticas que desempeñó inherentes a sus cargos. Pero más allá de estos papeles meramente accidentales, el zaragozano realizó diversos trabajos de importancia que me limito a consignar y poco más ${ }^{29}$.

${ }^{28}$ Además de ser Secretario Segundo, Lezaún perteneció a las tres Juntas Particulares que funcionaron en la Sociedad: fue Secretario de la Clase de Agricultura y agregado de las de Arte y Comercio. Por si fuera poco, también intervino en comisiones ocasionales. Así, fue Secretario de la Junta para la navegación del Ebro y perteneció a la Junta de la Población del Reino. Véase, E. Viamonte Lucientes, Tomás Fermín de Lezaún en la Real Sociedad Económica Aragonesa de Amigos del País, Archivo de Filología Aragonesa, LVII-LVIII, 2001, págs. 49-70. Y para cuestiones generales, J. Pasqual de Quinto, Ob. cit.

${ }^{29}$ Los libros de Resoluciones en los que se refleja la actividad de Lezaún son los correspondientes a los años de 1776, 1777 y 1778. Manuscritos que, como es natural, se pueden consultar en la R.S.E.A.A.P. 
A don Tomás Fermín se debe la Empresa de la Sociedad, que fue seleccionada en la Junta del 30 de agosto de 1776, para representar el espíritu de la Económica, y que aún hoy timbra todo lo que le concierne ${ }^{30}$.

Lezaún presentó junto al señor Ximeno, el 7 de febrero de 1777 en la Junta de Agricultura, un Apuntamiento de Órdenes y Pragmáticas sobre el plantío de árboles. El informe se halla minuciosamente descrito en el libro de Resoluciones de 1778. Gracias al mismo podemos saber que se compone de una serie cronológica de las Reales Órdenes y Autos del Consejo, desde 1496 hasta los días de los autores, junto con una declaración contra los abusos que se toleran en tal materia, tanto en los Corregimientos como en la ciudad de Zaragoza, así como las ventajas que se derivarían si se hiciesen observar con escrúpulo las órdenes de los Corregidores.

En Junta del 28 de febrero de 1777, se lee un discurso de los señores Torres y Lezaún, que lleva fecha del 20 del mismo mes. Discurso que manifiesta los abusos de los jornaleros con detrimento de la agricultura y transgresión de los Estatutos y Providencias del Ilustrísimo Ayuntamiento. Es un papel que, básicamente, contiene una breve historia de las Reales Disposiciones que sobre el particular han sido emitidas desde los tiempos de Enrique II a los de Felipe V. Es trabajo inacabado sobre el que seguirán trabajando posteriormente Torres y Lezaún, y que será nuevamente presentado y leído en Juntas posteriores.

El 19 de septiembre de 1777 se forma en el seno de la Sociedad la Junta de la Población del Reino. El 5 de diciembre del mismo año se lee en Junta General un papel, firmado por los señores Torres, Ximeno, Días y Lezaún, sobre el método a seguir en la Junta de la Población para trabajar sistemáticamente en un asunto de tanta gravedad, tan beneficioso al Estado.

En la Junta del 21 de enero de 1778 se nos informa de que Lezaún y don Ramón de Pignatelli se hallan trabajando en un Informe sobre los plantíos, que se lee, se aprueba y se decide dirigirlo a la superioridad del Consejo el 6 de febrero de 1778.

Vemos, por lo tanto, que además de las labores burocráticas de las que tenemos constancia manuscrita en los diversos libros de Resoluciones de la Sociedad, don Tomás Fermín de Lezaún realizó diversos trabajos, de mayor o menor peso, en el seno de la Económica Aragonesa, los cuales conservamos parcial o totalmente $^{31}$.

\footnotetext{
${ }^{30}$ Véase al respecto, E. Viamonte Lucientes, El emblema de la Económica Aragonesa y otros trabajos sobre representaciones simbólicas, en Actas I Congreso Internacional de Emblemática General, Zaragoza, Diputación Provincial, Institución Fernando el Católico, 2002, págs. 1279-1288.

${ }^{31}$ No quisiera dejar pasar este escrito para señalar a la Económica Aragonesa como una de las Sociedades de Amigos del País más pujantes. Sirva como refrendo el siguiente dato: lo libros de Resoluciones de
} 


\section{Conclusiones}

Éstas son todas las noticias que he podido recoger acerca de la vida y de la obra de don Tomás Fermín de Lezaún. Queda, como he dicho arriba, para mejor ocasión el estudio de su biblioteca y, sobre todo, el rastreo de los muchos estudios en los que Lezaún estuvo ocupado y de los cuales hoy no sabemos su paradero, además de atender con mayor detalle a sus labores conocidas, trabajo que, en lo que respecta a su abundante obra poética, me ocupa en la actualidad. Pero por encima de estas consideraciones, creo que es evidente que don Tomás Fermín de Lezaún y sus desvelos merecen salir del anonimato en el que hasta ahora prácticamente han estado.

la Sociedad Aragonesa, en el período que va de su fundación en 1776 al inicio de la Guerra de la Independencia en 1808, son un total de 34 con alrededor de 10.000 páginas manuscritas sobre sus innumerables desvelos. 